\title{
Blood pressure in Papua New Guinea: a survey of two highland villages in the Asaro Valley
}

\author{
HILARY KING, ${ }^{1}$ ANDREW COLLINS, ${ }^{2}$ LORRAINEF KING, ${ }^{1}$ PETER HEYWOOD, ${ }^{2}$ \\ MICHAEL ALPERS, ${ }^{2}$ JANICE COVENTRY, ${ }^{1}$ AND PAUL ZIMMET \\ From the WHO Collaborating Centre for the Epidemiology of Diabetes Mellitus, ${ }^{1}$ Royal Southern Memorial \\ Hospital, Melbourne, Australia and the Papua New Guinea Institute of Medical Research, ${ }^{2}$ Goroka, Papua New \\ Guinea
}

SUMMARY The results of a population survey of blood pressure in the adult residents of two highland villages in the Asaro Valley, Papua New Guinea are reported. The survey was conducted in 1983 as part of a wider epidemiological investigation of non-communicable disease in Papua New Guinea. Response to the survey was $95 \%$, and 308 subjects were examined. Population estimates of both systolic and diastolic blood pressures were low and there was a virtual absence of hypertension, as defined by internationally recommended criteria. There was no evidence of a rise in blood pressure with age, and the association between blood pressure and indices of obesity was weak. These findings are consistent with previous studies of blood pressure in traditional Papua New Guinean societies. The two villages differed with respect to their degree of modernisation. An unexpected finding was that in both sexes, both systolic and diastolic blood pressures were higher in the more traditional village. In each case, these differences were consistent across the three age groups examined, and they could not be explained by differences between the villages with respect to the indices of obesity. Analysis of variance showed that the higher blood pressures in the more traditional village were most unlikely to be due to chance $(p<0.001)$. The explanation for this finding remains obscure.

Hypertension appears to have been uncommon in traditional Melanesian societies, including those of Papua New Guinea. ${ }^{1-3}$ However, much of the evidence has been based on clinical records and on early field studies which predated internationally standardised survey methods. ${ }^{4}$

These former studies in Papua New Guinea suggested that the low prevalence of hypertension was associated with an absence of the age-related rise in blood pressure noted in western populations. ${ }^{12}$ The theory that a positive association between blood pressure and age may develop in such populations once they have been exposed to the process of modernisation of life-style was supported by a study of the urbanised, coastal Papuan residents of Hanuabada Village in Port Moresby. ${ }^{1}$ Coastal and highland populations in Papua New Guinea are, however, known to differ with respect to ancestral genetic admixture. ${ }^{5}$ The consequence of recent modernising influences on blood pressure in highland populations has not previously been examined.

Because of the remoteness of their location, the large populations living in the highland valleys of
Papua New Guinea were not exposed to western influence until the 1930s.

In the past 30 years, development and commerce have spread rapidly in the highland valleys, coffee and tea production providing an important economic incentive. Access to the Eastern Highlands Province, the centre of coffec production and the most developed of the five highland provinces, is now possible by daily jet aircraft, as well as by road from the coastal towns of Lae and Madang. The commercial and administrative centre of the Eastern Highlands Province is the town of Goroka, which lies at an altitude of $1560 \mathrm{~m}$ in the Asaro Valley.

In the present report, a study of blood pressure in the residents of two villages in the Asaro Valley is described. The survey was an initial exercise in a wider investigation of non-communicable disease in Papua New Guinea.

\section{Subjects and methods}

The study sample consisted of the total adult (20 years and over) population of the two villages in the 
Asaro Valley not far from the town of Goroka. The villages were chosen because preliminary dietary data had been collected in the two villages by the Papua New Guinea Institute of Medical Research. Both villages had also indicated their interest in participating in a prospective study of non-communicable disease. The survey was conducted in June 1983.

The two villages differed in their degree of modernity. Whereas one village (Gamusi) was situated at an altitude of $2000 \mathrm{~m}$ and could be reached only by a difficult and sometimes impassable road, the other village (Gimisave) lay in the valley floor at an altitude of $1700 \mathrm{~m}$ and was situated beside the Highlands Highway, the major route for land transport in the country.

Nutritional studies had already demonstrated a more traditional diet at Gamusi-though some non-traditional elements in the diet had been observed in both villages. Both villages are now involved in the cash economy, and in coffee production. Commercial enterprise is more evident in Gimisave, where it has led to limited affluence. Coffee growing has contributed to the Gimisave economy for a number of years.

As survey work was conducted during the coffee-picking season, some of the younger adults were away from the area at the time of the study. Any bias produced by the absence of these subjects would lead to an overestimate of the prevalence of a chronic disease which becomes more frequent with advancing age.

The age of each subject was estimated indirectly, taking into account the ages of children and/or grandchildren and questions relating to key historical events of local significance and known date. As such age estimates were necessarily crude, age-specific data have been analysed using three broad age groups: $20-29,30-44$, and 45 years and over. The points of division correspond approximately to terciles of the age distribution of the total survey population.

Blood pressure was measured on the right arm after the subject had been seated for ten minutes or more. A Hawksley random-zero sphygmomanometer was used, ${ }^{6}$ the mean of two successive blood pressure readings being recorded. When the two readings differed by more than $10 \mathrm{mmHg}$ a third reading was taken, and the median of the three readings was recorded. Diastolic pressure was recorded at phase five (disappearance of sounds).

Height, weight, and triceps and subscapular skinfold thicknesses were recorded in all subjects with the exception of one elderly woman who was unable to stand. Body mass index was calculated as weight/height squared $\left(\mathrm{kg} / \mathrm{m}^{2}\right)$.

A census was conducted in each village immediately before the survey. There was a total of 329 adults present in the two villages, of whom five were too frail to reach the survey site. Of the remaining 324 subjects, 308 attended the survey, a response rate of $95 \%$.

\section{Results}

Means and standard deviations for systolic and diastolic blood pressure are shown in table 1. Mean pressures were notably low, mean systolic failing to reach $120 \mathrm{mmHg}$ and mean diastolic failing to reach $70 \mathrm{mmHg}$ even in those aged 45 years or over. Defining hypertension according to recently recommended WHO criteria (systolic pressure $\geqslant 160 \mathrm{mmHg}$ and/or diastolic pressure $\geqslant 95 \mathrm{~mm} \mathrm{Hg}$ ), ${ }^{7}$ only four of the 308 subjects examined were hypertensive.

Table 1 Mean and standard deviation of systolic and diastolic blood pressures by age, sex, and village. Asaro Valley, Papua New Guinea, 1983

\begin{tabular}{|c|c|c|c|c|c|c|c|}
\hline \multirow[b]{2}{*}{$\begin{array}{l}\text { Age } \\
\text { (years) }\end{array}$} & \multicolumn{3}{|c|}{ Gamusi } & \multicolumn{4}{|c|}{ Gimisave } \\
\hline & No & $\begin{array}{l}\text { Systolic } \\
\text { mean (sd) }\end{array}$ & $\begin{array}{l}\text { Diastolic } \\
\text { mean (sd) }\end{array}$ & No & $\begin{array}{l}\text { Systolic } \\
\text { mean (sd }\end{array}$ & d) & $\begin{array}{l}\text { Diastolic } \\
\text { mean (sd) }\end{array}$ \\
\hline \multicolumn{8}{|l|}{ Men } \\
\hline $20-29$ & 36 & $114.3(13 \cdot 1)$ & $67.9(12.8)$ & 11 & $107.6 \quad$ & $(14 \cdot 5)$ & $60.8(7.6)$ \\
\hline $30-44$ & 23 & $112.7(12 \cdot 3)$ & $68.1(9.7)$ & 12 & $106 \cdot 8$ & $(13 \cdot 2)$ & $64 \cdot 1(13 \cdot 2)$ \\
\hline $45+$ & 38 & $113.3(13.8)$ & $66.2(9.5)$ & 24 & 107.2 & $(15 \cdot 2)$ & $61 \cdot 1(11 \cdot 3)$ \\
\hline \multicolumn{8}{|l|}{ Women } \\
\hline $20-29$ & 29 & $109 \cdot 8(11 \cdot 1)$ & $65.3(8.6)$ & 17 & 97.0 & $(12 \cdot 6)$ & $56 \cdot 7(11 \cdot 2)$ \\
\hline $30-44$ & 29 & $107.0(8.8)$ & $63.5(10.0)$ & 32 & 95.1 & $(14 \cdot 0)$ & $51 \cdot 1(10 \cdot 8)$ \\
\hline $45+$ & 32 & $108 \cdot 1(19 \cdot 3)$ & $59.3(10.6)$ & 24 & 103.9 & $(21 \cdot 3)$ & $58.9(15.0)$ \\
\hline
\end{tabular}

In neither sex and neither village was there evidence of a strong trend with advancing age. However, at each age group, within villages, women had lower mean pressures than men. Furthermore, age-sex-specific mean pressures were higher in Gamusi than in Gimisave in every case. Thus, after allowing for age and sex differences, both mean systolic and diastolic pressures were higher in the more traditional village.

Means and measures of dispersion of the two indices of adiposity (body mass index (BMI) and sum of triceps and subscapular skinfold thicknesses) are shown in table 2 . For mean BMI, there was little difference between the sexes or between villages. 
Table 2 Mean body mass index and sum of skinfold thicknesses (10th and 90th percentiles in parentheses). Asaro Valley, Papua New Guinea, 1983

\begin{tabular}{lll}
\hline $\begin{array}{l}\text { No examined/ } \\
\text { index of obesity }\end{array}$ & $\begin{array}{l}\text { Gamusi } \\
\text { mean }(10 t h, 90 t h \text { \%ole) }\end{array}$ & $\begin{array}{l}\text { Gimisave } \\
\text { mean (10th, 90th \%oll) }\end{array}$ \\
\hline Men & & 47 \\
No & 97 & $22(19,25)$ \\
Body mass index $\left(\mathrm{kg} / \mathrm{m}^{2}\right)$ & $22(20,24)$ & $18(13,24)$ \\
Sum of skinfolds $(\mathrm{mm})$ & $16(12,21)$ & \\
Women & & 73 \\
No & 90 & $22(20,25)$ \\
Body mass index $\left(\mathrm{kg} / \mathrm{m}^{2}\right)$ & $21(19,25)$ & $26(17,37)$ \\
Sum of skinfolds $(\mathrm{mm})$ & $23(12,35)$ & \\
\hline
\end{tabular}

Mean sum of skinfolds was higher in women than in men, and in Gimisave than in Gamusi, the latter finding suggesting that the higher mean blood pressures noted in Gamusi subjects were not directly related to adiposity. Subjectively, most subjects were noted to be lean and muscular, and values for BMI may to some extent reflect the latter characteristic. However, studies in other Melanesian populations have shown that BMI retains its utility as a measure of adiposity for within population comparisons in such communities. ${ }^{8}$

Confounding of BMI as a measure of adiposity by muscularity would tend toward overestimation. Despite this, the estimates given in table 2 show the residents of both villages to be lean by international standards and the population distribution of these indices to be narrow in range. Median values of BMI and sum of skinfolds were also examined, and the findings were comparable.

Coefficients of linear correlation between blood pressure and age and the indices of adiposity are shown in table 3. Though all were low, there was evidence of weak correlation between BMI and both systolic and diastolic pressure in Gimisave, and between BMI and diastolic pressure in Gamusi. In

Table 3 Coefficients of linear correlation between systolic and diastolic blood pressures and selected variables. Asaro Valley, Papua New Guinea, 1983

\begin{tabular}{llc}
\hline & Systolic & Diastolic \\
\hline Gamusi & & \\
Age (years) & 0.02 & -0.16 \\
Body mass index $\left(\mathrm{kg} / \mathrm{m}^{2}\right)$ & 0.09 & 0.19 \\
Sum of skinfolds $(\mathrm{mm})$ & 0.04 & 0.09 \\
Gimisave & & \\
Age (years) & 0.13 & 0.06 \\
Body mass index $\left(\mathrm{kg} / \mathrm{m}^{2}\right)$ & 0.22 & 0.21 \\
Sum of skinfolds $(\mathrm{mm})$ & 0.05 & 0.15 \\
\hline
\end{tabular}

almost every case the correlation coefficient for Gamusi was weaker than the corresponding coefficient for Gimisave.

Trends across groups of increasing age and adiposity are shown in the figure. The curves are notably flat. Most obvious is the highly consistent difference between the two villages, mean blood pressure being higher in Gamusi, the more traditional village, in every cse.

A strong negative association between age and adiposity, which is characteristic of traditional communities, has previously been reported in this study population. ${ }^{9}$ Coefficients of linear correlation between age and BMI were $\mathrm{r}=-0.4$ for men and $r=-0.6$ for women. In order to eliminate possible
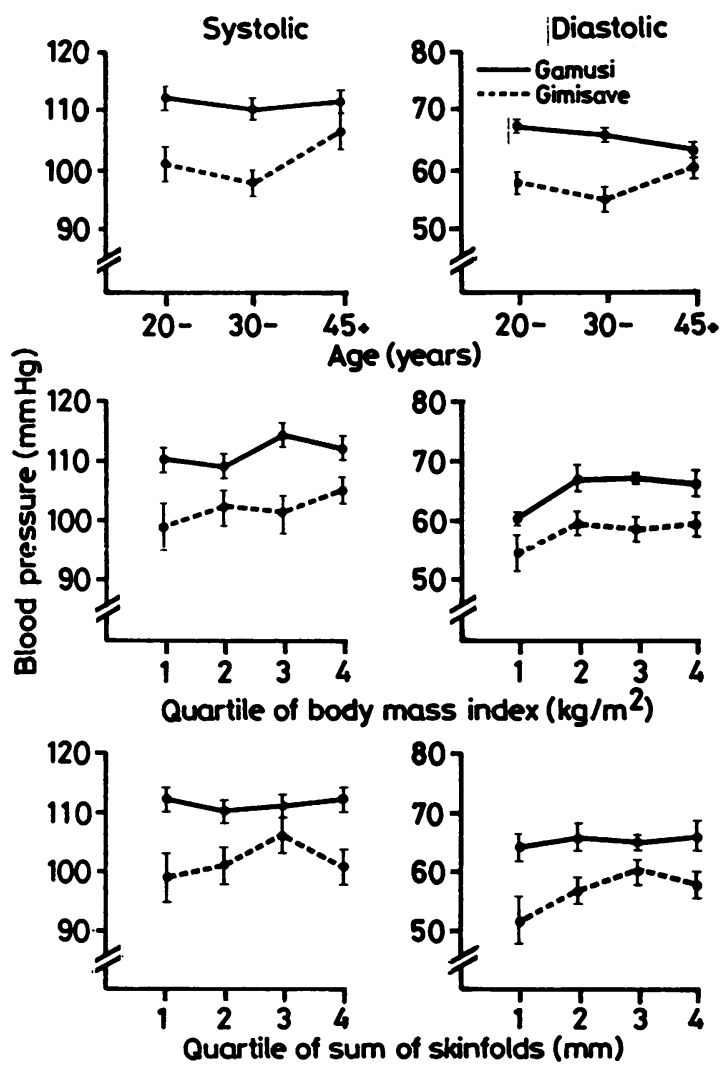

Mean \pm SEM systolic and diastolic blood pressures in groups of increasing age, body mass index, ${ }^{*}$ and sum of skinfold thicknesses †. Asaro Valley, Papua New Guinea, 1983.

${ }^{*} Q u a r t i l e s$ of body mass index $\left(\mathrm{kg} / \mathrm{m}^{2}\right)$ $Q_{1}=20 \cdot 5, Q_{2}=21 \cdot 8, Q_{3}=23 \cdot 5$.

†Quartiles of skinfold thicknesses $(\mathrm{mm})$

$$
Q_{1}=15 \quad Q_{2}=19 \quad Q_{3}=25
$$


confounding of a putative relation between blood pressure and age by adiposity, and between blood pressure and adiposity by age, analysis of variance was performed (table 4). Village of residence and sex were independently associated with both systolic and diastolic pressure $(p \leqslant 0 \cdot 001)$. There was a weak, but independent association between BMI and diastolic pressure $(p=0.02)$. Once again there was no evidence for an age effect on either systolic or diastolic blood pressure.

Table 4 Analysis of variance of systolic and diastolic blood pressures by village of residence, age group, interquartile group of body mass index and sex. Asaro Valley, Papua New Guinea, 1983

\begin{tabular}{|c|c|c|c|c|}
\hline \multirow{2}{*}{$\frac{\text { Variable }}{\text { Systolic blood pressure }}$} & \multicolumn{2}{|c|}{ Sum of squares $d f$} & \multirow[t]{2}{*}{$F$} & \multirow[t]{2}{*}{$p$} \\
\hline & & & & \\
\hline \multicolumn{5}{|l|}{ Main effects: } \\
\hline $\begin{array}{l}\text { Village of residence } \\
\text { Age group } \\
\text { Interquartile group of } \\
\text { body mass index } \\
\text { Sex }\end{array}$ & $\begin{array}{r}5147 \cdot 8 \\
725 \cdot 8\end{array}$ & $\begin{array}{l}1 \\
2\end{array}$ & $\begin{array}{r}24 \cdot 7 \\
1 \cdot 7\end{array}$ & $\begin{array}{c}<0.001 \\
\text { NS }\end{array}$ \\
\hline \multicolumn{5}{|l|}{ Main effects: } \\
\hline $\begin{array}{l}\text { Village of residence } \\
\text { Age group } \\
\text { Interquartile group of } \\
\text { body mass index } \\
\text { Sex }\end{array}$ & $\begin{array}{r}3289 \cdot 2 \\
108 \cdot 7\end{array}$ & $\begin{array}{l}1 \\
2\end{array}$ & $\begin{array}{r}27 \cdot 3 \\
0.5\end{array}$ & $\begin{array}{c}<0.001 \\
\text { NS }\end{array}$ \\
\hline
\end{tabular}

\section{Discussion}

The results of this study reinforce earlier reports of low mean blood pressure and a virtual absence of hypertension in Papua New Guinea highlanders. There was little evidence of an association between either age or adiposity and blood pressure, although it should be remembered that these populations undertake a high level of habitual activity, in a high altitude setting, and obesity is uncommon.

If a critical level of adiposity is required before blood pressure is influenced by adiposity, the apparent lack of association between these two variables may have been due to very few subjects attaining such a level. Furthermore, the narrow range of the distribution of the indices of adiposity would have constrained their potential power in the analyses performed in this study. Alternatively, it may be that the strong negative association noted between age and adiposity may have prevented a more complex interaction operating between these two variables to produce the rise with age noted in western populations.

The emergence of hypertension after sociocultural modernisation in societies in which the disease is apparently rare in the traditional setting has been described with consistency in many ethnic groups living in geographically and environmentally diverse locations. ${ }^{10-17} \mathrm{~A}$ former study of blood pressure in several Melanesian societies ${ }^{3}$ also showed lower pressures in the more traditional groups. The finding, in the present study, of higher estimates of blood pressure in the more traditional of the two villages examined was therefore most unexpected. The difference between villages applied to both sexes, did not appear to be due to confounding by obesity, and was very unlikely to have been due to chance. However, since considerable genetic heterogeneity can be expected among small population isolates in the highlands of Papua New Guinea, it will be important to examine other groups before ascribing the observed difference in blood pressure levels between these two villages to social and environmental factors.

Although an inverse relation was recently $\stackrel{0}{+}$ demonstrated between blood pressure and $\underset{0}{0} \vec{G}$ socioeconomic status in the US population, ${ }^{18}$ we are $\stackrel{\Phi}{\Phi}$ 을 not aware that such an association has been $\frac{?}{\mathbb{D}} \vec{T}$ documented in a relatively traditional setting, such as $\varrho$ the Papua New Guinea highlands. The explanation $\mathbb{D}$ for this finding is at present obscure, although genetic 8 요 difference or a dietary change-for example, the $\frac{0}{0}$ replacement of the traditional staple sweet potato byco white rice, which possesses a lower salt content-or a? greater degree of stress in the more marginal environment of Gamusi may be advanced as possibilities.

Hypotheses relating to salt and other dietary components could not be examined directly in the present study, as data collected during the Asaro Valley survey did not include estimates of dietary intake or of sodium excretion. However, future studies planned in this and other communities in Papua New Guinea may shed further light on the determinants of blood pressure in these populations. There are now very few societies in the world in which life remains relatively traditional and in which non-communicable diseases are still rare. The longitudinal study of physiological characteristics such as blood pressure during the rapid modernisation which these communities are presently experiencing may lead to insight regarding the genesis of non-communicable disease which they alone can now provide.

This study was a collaborative project between the WHO Collaborating Centre for the Epidemiology of 
Diabetes Mellitus, Royal Southern Memorial Hospital, Melbourne, Australia and the Institute of Medical Research, Goroka, Papua New Guinea. The study was supported by NIH grant No. 1 RO1 AM25446. We acknowledge the support of $\mathrm{Mr} B$ Carrad, of the Department of Primary Industry, and the assistance of Mr R Spark with the field work.

Requests for reprints to: $\mathrm{Dr} \mathrm{H}$ King, WHO Collaborating Centre of the Epidemiology of Diabetes Mellitus, Royal Southern Memorial Hospital, PO Box 185, South Caulfield, Victoria, 3162, Australia.

\section{References}

${ }^{1}$ Maddocks I. Blood pressures in Melanesians. Med J Aust 1967; 1: 1123-6.

${ }^{2}$ Sinnett PF, Whyte HM. Epidemiological studies in a total highland population, Tukisenta, New Guinea. J Chron Dis 1973; 26: 265-90.

${ }^{3}$ Page LB, Damon A, Moellering RC. Antecedents of cardiovascular disease in six Solomon Islands societies. Circulation 1974; 49: 1132-46.

${ }^{4}$ Rose GA, Blackburn H. Cardiovascular survey methods. Geneva: World Health Organisation, 1968.

${ }^{5}$ Serjeantson SW, Kirk RL, Booth P. Linguistic and genetic differentiation in New Guinea. J Hum Evol 1983; 12: 77-92.

${ }^{6}$ Wright BM, Dore CF. A random zero device. Lancet 1970; i: 337-8.
${ }^{7}$ World Health Organisation. Arterial hypertension. Geneva: WHO, 1978 (Technical Report Series No 628).

${ }^{8}$ Zimmet $\mathbf{P}$, Taylor R, Ram P, et al. Prevalence of diabetes and impaired glucose tolerance in the biracial (Melanesian and Indian) population of Fiji: a rural-urban comparison. Am J Epidemiol 1983; 118: 673-88.

${ }^{9} \mathrm{King} \mathrm{H}$, Heywood $\mathrm{P}$, Zimmet $\mathrm{P}$, et al. Glucose tolerance in a highland population in Papua New Guinea. Diabetes Research 1984; 1: 45-51.

${ }^{10}$ Cruz-Coke $R$, Etcheverry $R$, Nagel $R$. Influence of migration on blood pressure of Eastern Islanders. Lancet 1964; i: 697-9.

${ }^{11}$ Labarthe D, Reed D, Stallones R. Health effects of modernisation in Palau. Am J Epidemiol 1973; 98: 161-74.

${ }^{12}$ Beaglehole R, Eyles E, Salmond C, Prior I. Blood pressure in Tokelauan children in two contrasting environments. Am J Epidemiol 1975; 108: 283-8.

${ }^{13}$ Zimmet P, Taylor R, Jackson L, Whitehouse SL, Faaivaso $\mathrm{S}$, Ainuu J. Blood pressure studies in rural and urban Western Samoa. Med J Aust 1980; 2: 202-5.

${ }^{14}$ Trowell HC. In: Trowell HC, Burkitt DP, eds. Western diseases: their emergence and prevention. London: Edward Arnold, 1981; 3-32.

${ }^{15}$ Seedat YK, Seedat MA, Hackland DBT. Prevalence of hypertension in the urban and rural Zulu. $J$ Epidemiol Community Health 1982; 36: 256-61.

${ }^{16}$ Patrick RC, Prior IAM, Smith JC, Smith AH. Relationship between blood pressure and modernity in Ponapeans. Int $J$ Epidemiol 1983; 12: 36-44.

${ }^{17}$ Rao PSS, Inbaraj SG, Subramaniam VR. Blood pressure measures among women in South India. $J$ Epidemiol Community Health 1984; 38: 49-53.

${ }^{18}$ Harlan WR, Hull AL, Schmouder RL, Landis JR, Thompson FE, Larkin FA. Blood pressure and nutrition in adults: the national health and nutrition examination survey. Am J Epidemiol 1984; 120: 17-28. 